\title{
Humanities special studies modules: making better doctors or just happier ones?
}

Richard Meakin and Deborah Kirklin Royal Free and University College Medical School, London

"... the sensitivity of the artist may equal the knowledge of the scientist. Both have the same object, nature, and perhaps in time it will be possible for them to link together in a great and marvellous force which is at present hard to imagine."

These are exciting times for medical humanities in the UK, with artists and scientists working hand in hand to help deliver a more humanistic approach to health care. ${ }^{2}$ The existence of this journal and the wealth of innovative work it reports in this issue bear testimony to the enthusiasm and creativity of those active in the field. Throughout the country educators are taking up the challenge contained in the General Medical Council's (GMC) Tomorrow's Doctors ${ }^{3}$ and are developing and delivering humanities special study modules (SSMs) to complement the core medical curriculum. Specialists in literature, fine art, drama and medical history are bringing their expertise and enthusiasm to bear on the training of future health professionals. As a result productive and promising collaborations are taking place across traditional disciplinary boundaries. ${ }^{4}{ }^{5}$ In addition the humanities are being used educationally at postgraduate level and as part of continuing professional development. Educators in this field believe that well-designed humanities special study modules allow students to gain an improved understanding of the world within which their patients live and the role they as professionals must fulfil when invited into that world. ${ }^{5}$ Studying the humanities is thought to improve student understanding of the experiences and perspectives of patients, families and professionals and to improve empathetic skills. In turn it is thought that this will encourage professionally appropriate attitudes, improved communication, enhanced clinical care and renewed motivation of students to learn and do their best for those in their care. ${ }^{4}$ This at least is the theory and an appealing one at that. Anecdotal reports tell of high acceptability amongst both students and tutors and there is a general sense of optimism and promise within this embryonic academic community.

The time has now come to move beyond theories and anecdotes and there is a growing awareness that medical humanities courses must be subject to the same rigorous evaluation as all other aspects of medical education. ${ }^{78}$ The GMC have encouraged this approach by making it clear that the SSMs should "aim high" in their educational aspirations and should in no way be seen as secondary in importance to the core subjects. Indeed they have stated very clearly that both students and educators should recognise the SSMs and the core subjects as providing equally important elements of the education of future doctors. ${ }^{2}$ They acknowledge that if this is to be so then educators will need to develop appropriate evaluative methods, not only to assess student achievement but also to demonstrate the effectiveness of this form of teaching in meeting the educational objectives laid down by the GMC.

The first step towards achieving these objectives needs to be the sharing of ideas and experiences throughout the field and across disciplines. This section of Medical Humanities aims to provide a venue for this interchange so that we can practise as educators what we preach and learn from each others' stories and experiences. The next step will be the development and objective evaluation of assessment tools, which we can then use to decide and demonstrate which of our humanities courses merit support from medical schools and which, perhaps, do not.

This is the challenge now facing us and to which we must respond if we, as artists and scientists, are to do our part in translating Chekhov's vision into a reality.

Work in this area will be beginning shortly in the medical humanities unit and researchers 
50 Humanities special studies modules: making better doctors or just happier ones?

interested in contributing to this work are encouraged to contact Deborah Kirklin at the address below.

Richard Meakin is Senior Lecturer and Director of the Medical Humanities Unit, Department of Primary Care and Population Sciences, Royal Free andUniversity College Medical School, London. Deborah Kirklin is Lecturer in Medical Humanities and Clinical Lecturer in Communication Skills, the Medical Humanities Unit, Department of Primary Care and Population Sciences, Royal Free and University College Medical School, London. Address for correspondence: Dr D Kirklin, the Medical Humanities Unit, Department of Primary Care and Population Sciences, Royal Free Campus, Rowland Hill Street, London NW3 $2 P F$

\section{References}

1 Coope J. Quoting from: Chekhov A. Draft of a letter to Gregorovitch. Doctor Chekhov - a study in literature and medicine. Isle of Wight: Cross Publishing, 1997: ch 3: 49.

2 Knight S. Council aims to integrate arts and humanities into the NHS. British Medical fournal 1999;319:1222.

3 General Medical Council. Tomorrow's doctors - recommendations on undergraduate medical education. London: General Medical Council, 1993.

4 Downie RS, Hendry RA, Macnaughton RJ, Smith BH. Humanising medicine: a special study module. Medical Education 1997;31,4:276 - 80.

5 Kirklin D, Meakin R, Singh S, Lloyd M. Living with and dying from cancer: a humanities special study module. Medical Humanities 2000;1:

6 Bolton G. Stories at work: reflective writing for practitioners. Lancet 1999;354:243-5.

7 Hutchinson L. Evaluating and researching the effectiveness of educational interventions. British Medical fournal 1999;318: 1267-9.

8 Wikes M, Bligh J. Evaluating educational interventions. British Medical fournal 1999;318:1269-72. 